\title{
The measurement of thermal changes on concrete box girder bridge
}

\author{
Lukáš Krkoška ${ }^{1, *}$, Martin Moravčík ${ }^{1}$ \\ ${ }^{1}$ University of Zilina, Faculty of Civil Engineering, Department of Structures and Bridges, \\ Univerzitna 2, 01026 Žilina, Slovakia
}

\begin{abstract}
Thermal load, especially vertical temperature gradient is an important factor that should be considered during the bridge design procedure. In the world several researches focusing on thermal influences was performed, mostly in USA and China, but only a few analysed real measured cross-section temperature gradient at European bridges. In this paper, the temperature field along two decisive cross-section of concrete box girder bridge caused by heat of hydration or exposure to sunlight has been investigated by field monitoring. The measured temperature gradients has been compared to the Slovak bridge design eurocode.
\end{abstract}

\section{Introduction}

In practice, the variations of temperature affects bridges significantly. Uniform temperature changes cause large total length changes, expansion or contraction. These changes of length influence internal forces, structural dynamic characteristics and the continuous expansion and contraction may damage critical members of the bridge, such as expansion joint, bearing and anchor head. If these deformations are restricted, temperature variations result in thermal stresses, what may leads to unexpected tensile cracks and consequent possible reinforcement corrosion. Vertical and horizontal temperature difference result in additional bending moments in vertical plane and horizontal plane, respectively.

\section{Bridge and Monitoring System Description}

In this paper it is analyzed the prestressed concrete box girder highway bridge structure SO201-10, highway part from Hricovske Podhradie to Lietavska Lucka. Bridge has nine spans $(48.0 \mathrm{~m}+3 \times 58.0 \mathrm{~m}+60.0 \mathrm{~m}+2 \times 68.0 \mathrm{~m}+54.0 \mathrm{~m}+37.1 \mathrm{~m})$, with total length of $835.1 \mathrm{~m}$, built by incremental launching method. The main spans $(68.0 \mathrm{~m})$ bridging the highway and railway. The length of steel launching nose is $39.0 \mathrm{~m}$, see Figure 2 . The deck of the bridge consists of a continuous box girder seated on simple bearings on the piers and abutments. Width of the top slab is $13.75 \mathrm{~m}$ and the bottom slab is $8.0 \mathrm{~m}$. The height of the single cell box cross-section is variable, from $3.85 \mathrm{~m}$ to $4.5 \mathrm{~m}$. Thickness of the webs varies

* Corresponding author: lukas.krkoska@fstav.uniza.sk 
from $450 \mathrm{~mm}$ (middle of span) to $1000 \mathrm{~mm}$ (above the supports). The top and bottom slabs have constant thickness $300 \mathrm{~mm}$ with $500 \mathrm{~mm}$ haunches $1.5 \mathrm{~m}$ from the webs.

During the construction of the bridge, total 19 embedment vibrating wire strain gauges for concrete, 8 thermocouples and 2 air thermometers were arranged at two characteristic cross sections of the first span, as shown in Figs. 1 3. The first measured cross-section (MP1) is approximately at $3 / 5$ of the first span and second measured cross-section (MP2) is very next to the sleeper. Vibrating wire strain gauges type TES/5.5/T are able to measure strain (as the function of measured value) and temperature. In cross-section MP1 we have measured strains and temperature of the concrete (S1 S7) and in cross-section MP2 we have measured the strains and temperature of the concrete $(\mathrm{S} 1 \sim \mathrm{S} 11)$, the temperature of the concrete surface (TP1 TP7), temperature of the interior and exterior air (TE1, TE2) and the temperature of the web in depth $400 \mathrm{~mm}$ (TC400). All of these values was measured continually.

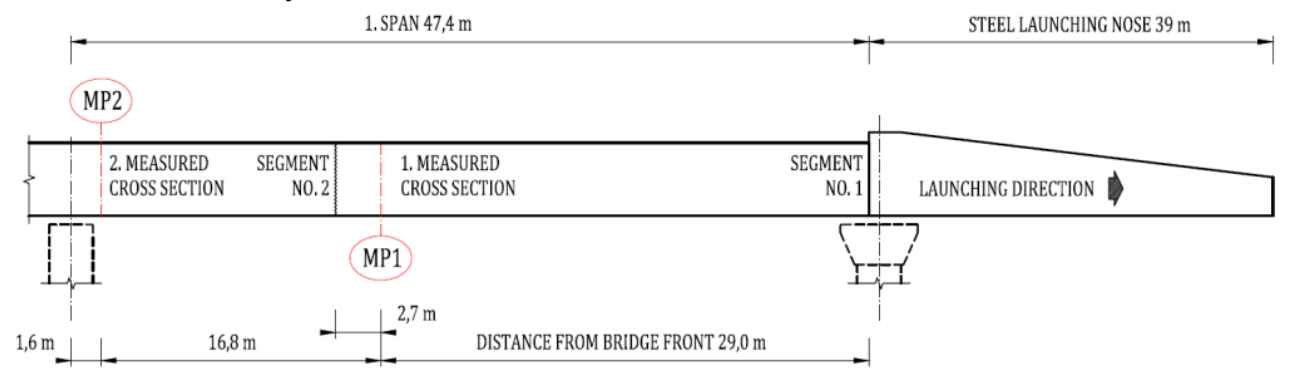

Fig. 1. Position of measured cross sections in longitudinal section.

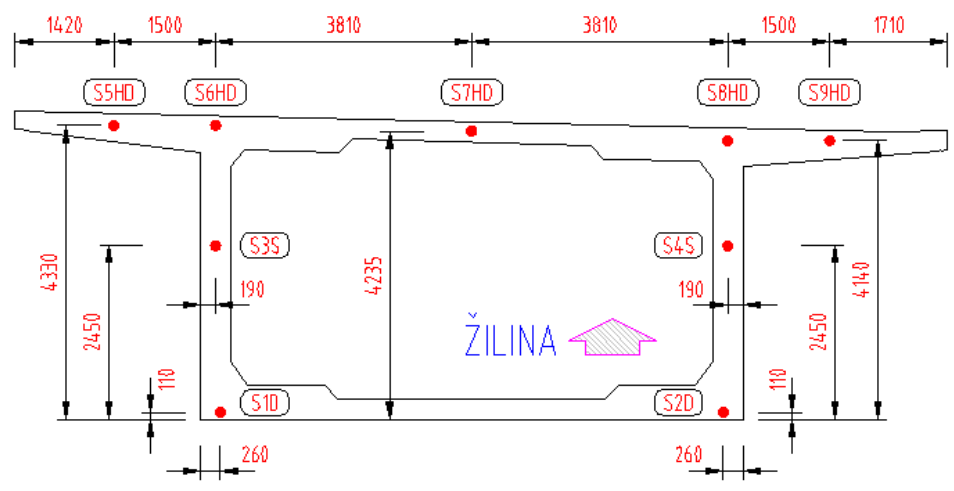

Fig. 2. Strain gauges arrangement at measured cross section MP1. 

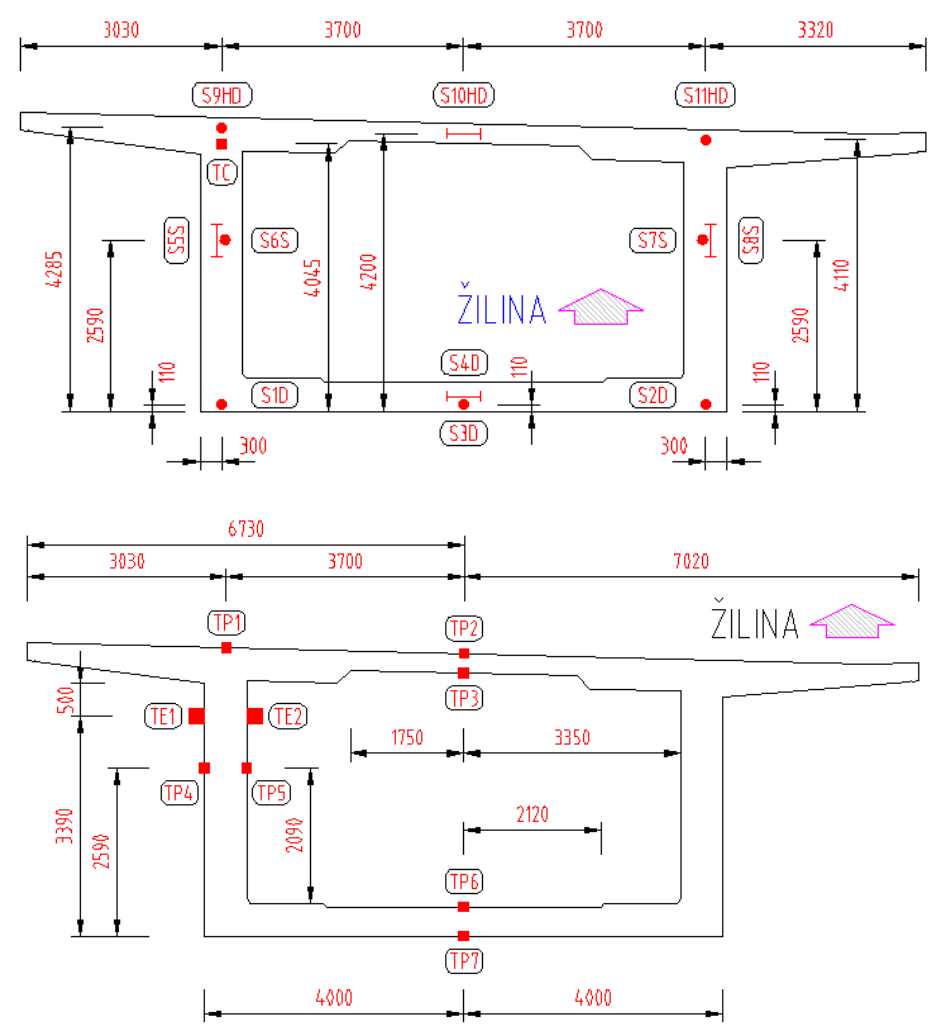

Fig. 3. Strain gauges and thermocouples arrangement at measured cross section MP2.

\section{Measurement results}

\subsection{Variation of temperature caused by hydration process of the concrete}

The concrete during the hydration produce a significant amount of hydration heat, what is clearly visible in Fig. 4. These figures shows the variation of temperature caused by concrete hydration in cross-section MP1. The temperature in concrete of bottom slabs and webs rises immediately after casting of the concrete and after hydration process decreases and regresses to the normal temperature of the air, seed Fig. 8. After 14 days was casted the top slab, which temperature rapidly rises due to produced hydration heat and after hydration process again decreases and regresses to the normal temperature of the air, see Fig. 4. 

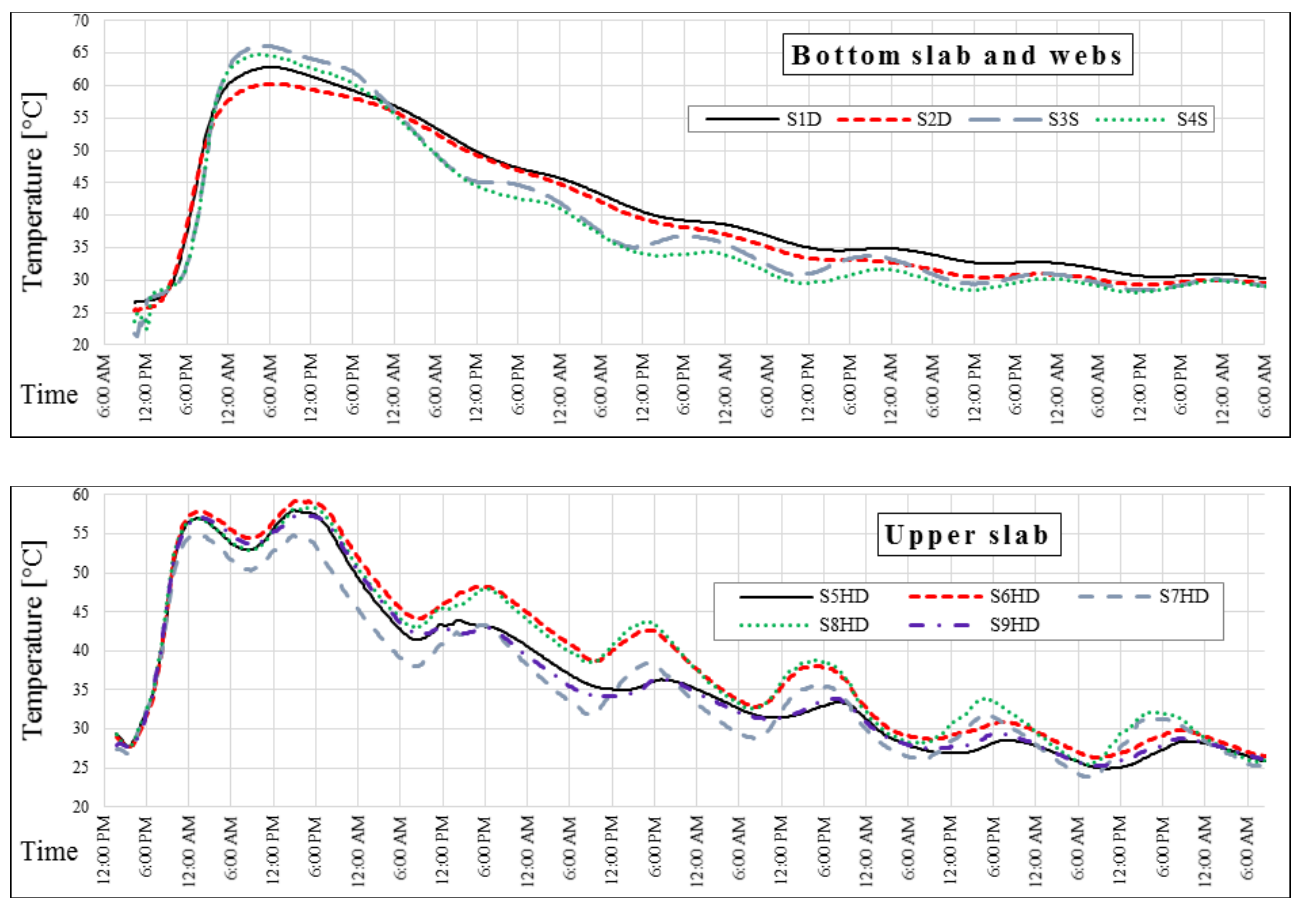

Fig. 4. Temperature in concrete of bottom slab, upper slab and web during the hydration process.

Field test results (see Fig. 4.) show that the variation of hydration heat temperature consist of four temperature periods during the hydration of concrete:

1. First $0-16 \mathrm{~h}$ after concrete casting, when temperature of the interior concrete reaches the peak value rapidly. The temperature increment is about $30^{\circ} \mathrm{C} \sim 35^{\circ} \mathrm{C}$.

2. 16-20 h after concrete casting, when temperature of the interior concrete is approximately stable about the peak value.

3. 20-48 h after concrete casting, when temperature decreases rapidly.

4. 48-96 $\mathrm{h}$ after concrete casting, when temperature slow falls and gradually regresses to the normal temperature of the air.

\subsection{Temperature variations caused by air temperature}

The variations in temperature of the concrete at the top and bottom slabs (gauges are about $110 \mathrm{~mm}$ beneaththe surface) as well as in the webs are shown in Fig. 5. This figure shows temperature of the concrete during three summer days from 10.8.2015 until 12.8.2015 with maximum day air temperature $36{ }^{\circ} \mathrm{C}$. The temperature of the interior concrete increases with air temperature, the rate of the rise in temperature of the top slab is the highest becauseof the perpendicular incidence of sunshine. Maximum measured temperature of the top and bottom slab was $38.04^{\circ} \mathrm{C}$ (at $16: 30 \mathrm{p} . \mathrm{m}$.) and $28.94^{\circ} \mathrm{C}$ (at $17: 30$ p.m.) respectively and the maximum temperature of the webs was $30.0^{\circ} \mathrm{C}$ (at 18:00 p.m.). The peak temperature induced by air temperature in the slabs and webs of the concrete box-girder lags by about $2 \sim 3 \mathrm{~h}$ behind the maximum air temperature, mainly because of the low thermal conductivity of concrete. It is clearly visible that measured temperature at the same level varies across the width (the difference of temperature of the top slab is $1.5^{\circ} \mathrm{C} \sim 5.0^{\circ} \mathrm{C}$ and difference in bottom slab and webs is about $1.0^{\circ} \mathrm{C}$ ), mainly because of different shading of the cross section and different angle of sunshine. 


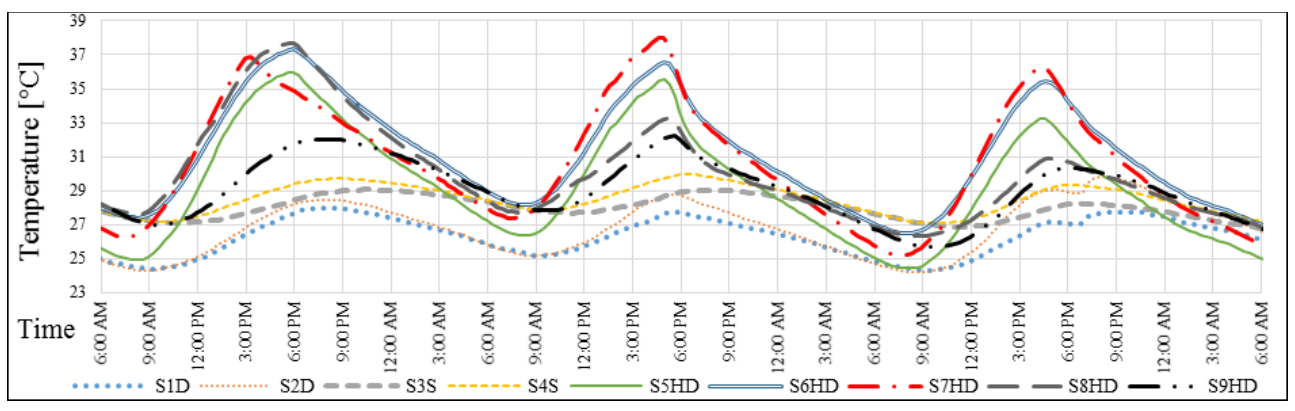

Fig. 5. Peak temperatures in concrete during summer days.

In Fig. 6 are shown the variations of temperatures of different cross-section parts during the period from 17.9.2015 to 19.9.2015. During this period the air temperature reached the maximum value from the date on which the surface thermocouples (TP1-TP7) were installed.

As the result of most intense solar radiation, the concrete temperature of the surface of upper slab of the box is higher than the air temperature outside of the box at the same time and the variations of these temperatures is consistent with each other, with a sinusoidal trend. The range of outer surface temperature was $12^{\circ} \mathrm{C}$. Because low thermal conductivity of concrete, the range of temperature changes of measuring points inside the concrete and at the inner surface is smaller $\left(6^{\circ} \mathrm{C}\right.$ and $4{ }^{\circ} \mathrm{C}$ respectively) and the peak temperature lags by about $2 \sim 3 \mathrm{~h}$ behind the maximum air temperature.

Due to shading of the flanges, the webs are not directly affected by the sun, when the sun is more intense. This caused that the temperature changes of the outer surface of the web correspond to changes of the air temperature outside of the box, with a deviation of less than $1^{\circ} \mathrm{C}$. Because the thickness of the web, the temperature inside the concrete and at the inner surface change slightly, with a daily fluctuation of less than $2{ }^{\circ} \mathrm{C}$.

The bottom slab is protected against solar radiation by upper slab and webs of box girder, so the temperature of the bottom slab is affected only by exterior air temperature. Temperature of outer surface does not reach the temperature of the exterior air and varies with a daily fluctuation of $7^{\circ} \mathrm{C}$. The temperature inside the concrete and at the inner surface change slightly, with a daily fluctuation of less than $3^{\circ} \mathrm{C}$. 

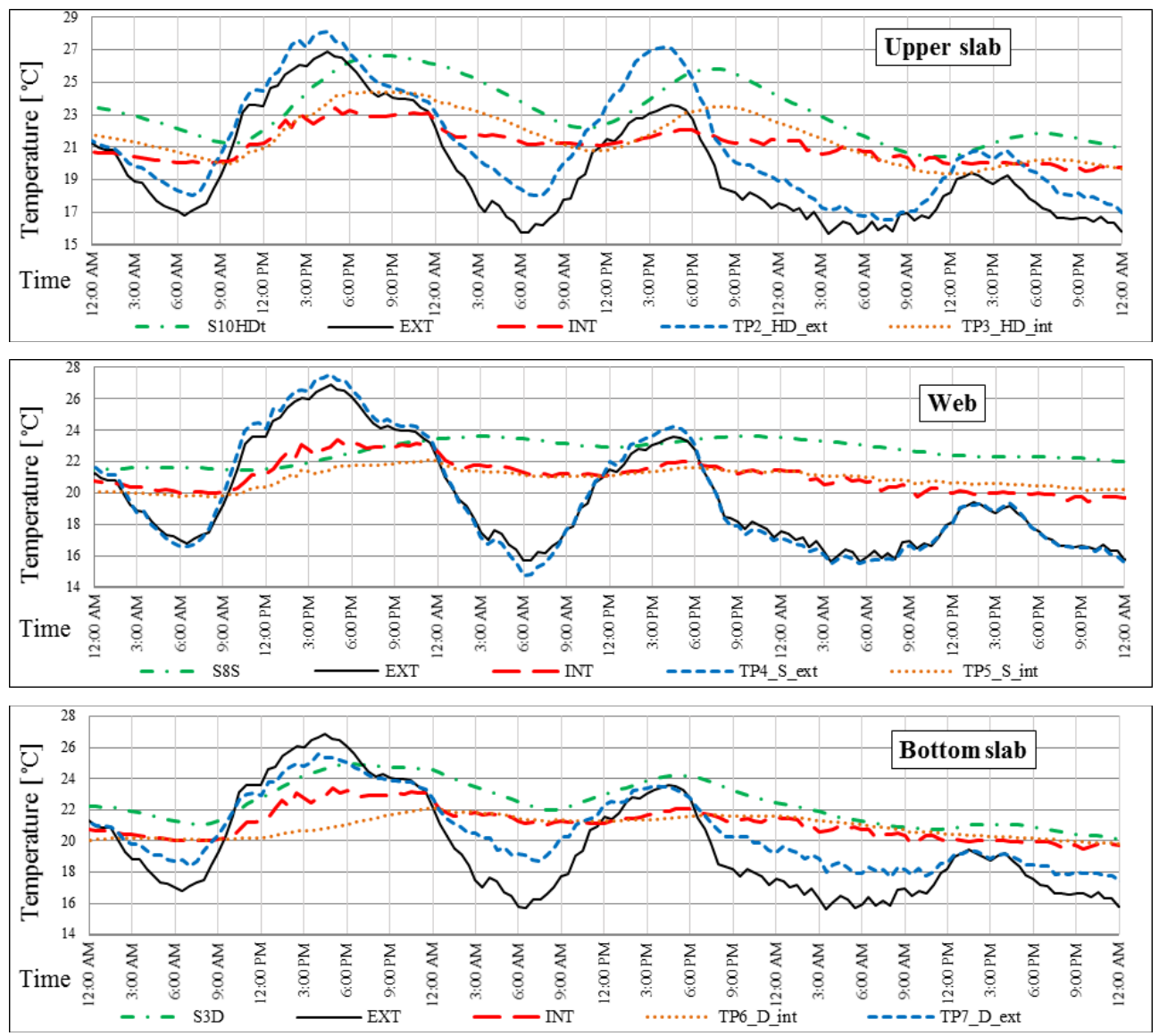

Fig. 6. Temperature changes in concrete at different parts of cross section.

\subsection{Distribution of temperature gradient}

The variation of air temperature may cause great temperature gradient, which can induce high thermal stress in the concrete box-girder. The vertical nonlinear temperature gradient obtained by subtracting a minimum temperature from the vertical temperatures along the depth of the cross section and comparison of these obtained gradients with temperature gradient for the same concrete box girder cross section recommended in Slovak bridge eurocode STN EN 1991-1-5 [6] are presented in Fig. 7. Maximum measured value of the positive temperature gradient at the top surface of the box-girder was $17.3^{\circ} \mathrm{C}$, while the value recommended in Slovak bridge eurocode for this shape of crosssection is only $15.4^{\circ} \mathrm{C}$. The distribution of the gradient is different from the recommended one and it is changing during the day with the temperature variations (see Fig. 6) The negative temperature gradient did not reach the recommended one, because the winter temperatures were very weak. 


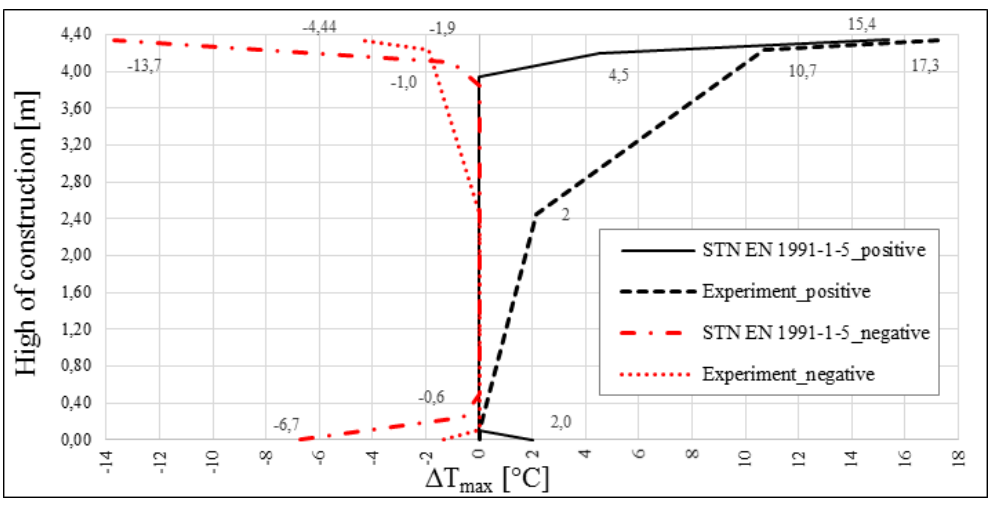

Fig. 7. Comparison of obtained temperature gradients with Slovak bridge eurocode.

\section{Conclusion}

The concrete during the hydration produce a significant amount of hydration heat what significantly impact on overall temperature and stress distribution of the concrete box-girder cross-section in early age of the concrete. The variation of hydration heat temperature consist of four periods: temperature rising period, constant temperature period, rapid temperature fall period and slow temperature fall period.

Caused by air temperature variations there are large temperature gradient over the height of the box-girder. The value of the temperature gradient can exceed the temperature gradient recommended in bridge standards specifications. Furthermore the temperature at the same level across the width is not constant, but varies, mainly because of different shading of the cross section and different angle of sunshine. This difficult temperature distribution may impact significantly the stress condition of the bridge and the tensile cracks can occur. Therefore is necessary to perform continuous temperature measurements and analysis of temperature gradient on bridge structures of various types, at least in periods with predicted maximum and minimum air temperatures.

The research is supported by the Slovak Research and Development Agency under contract No. APVV-0736-12 and by Research Project No. 1/0336/15 and 2/0033/15 of Slovak Grant Agency.

\section{References}

1. M. J. N. Priestley, Amer. Concrete Inst. Jour. 5, 209-217 (1978)

2. J. H. Emanuel, J. L. Hulsey, Jour. of the Struc. Div. 104(ST1), 65-78 (1987)

3. M. M. Elbadry, A. Ghali, Jour. of the Struc. Eng. 109(10), 2355-2374 (1983)

4. M. Emerson, Transp. Road Res. Lab. Sup. Rep. 747, 5-10 (1982)

5. STN EN 1991-1-5: Actions on Structures. Part 1-5: General Actions - Thermalactions (1991)

6. STN EN 1990: Eurocode. Basis of structural design (1990) 